\title{
POLÍTICAS PÚBLICAS TERRITORIAIS: A CRIAÇÃO DE NOVOS MUNICÍPIOS NO BRASIL
}

\author{
Territorial public policies: the creation of new municipalities in Brazil
}

Políticas públicas territoriales: la creación de nuevos municipios en Brasil

Lucas Batista Pereira ${ }^{1}$ http://orcid.org/0000-0002-6460-348X

\footnotetext{
${ }^{1}$ Professor Titular do Departamento de Geografia da Universidade Estadual do Sudoeste da Bahia - UESB, Vitória da Conquista - BA-Brasil, e-mail: lucabatistap@ig.com.br
}

\section{Resumo}

Este artigo tem por objetivo fazer uma análise sobre o Projeto de Lei Complementar 199/2015, aprovado pelo Senado Federal e em tramitação na Câmara Federal, que regulamenta a criação, desmembramento, fusão e incorporação de novos municípios no Brasil. Problematiza sobre três aspectos fundantes do Projeto de Lei: limites mínimos de população, Estudo de Viabilidade Municipal (EVP) e Referendum, considerando os dados do IBGE do Censo Demográfico de 2010 e previsão da população de 2015, bem como os critérios constantes no Projeto de Lei Complementar, foi feito um levantamento populacional de todos os 5.569 municípios e seus distritos. Com o levantamento desses dados foi possível fazer um mapeamento das possibilidades de criação de municípios, por Estado da federação e por regiões brasileiras.

Palavras-chave: Território. Congresso Nacional. Novos Municípios.

\begin{abstract}
This article aims to analyze the Complementary Law Bill 199/2015, approved by the Federal Senate and in process in the Federal Chamber, which regulates the creation, dismemberment, merger and incorporation of new municipalities in Brazil. Problematizes about three founding aspects of the Bill: minimum population limits, Municipal Feasibility Study (EVP) and Referendum. Considering the IBGE data of the Demographic Census of 2010 and population forecast of 2015, as well as the criteria included in the Complementary Law Bill, a population survey was made of all 5,569 municipalities and their districts. With the survey of these data it was possible to map the possibilities of creating municipalities, by State of the federation and by Brazilian regions.
\end{abstract}

Keywords: Territory. National Congress. New Municipalities. 


\section{Resumen}

Este artículo tiene por objetivo hacer un análisis sobre el Proyecto de Ley Complementaria 199/2015, aprobado por el Senado Federal y en tramitación en la Cámara Federal, que regula la creación, desmembramiento, fusión e incorporación de nuevos municipios en Brasil. Problematiza sobre tres aspectos fundantes del Proyecto de Ley: límites mínimos de población, Estudio de Viabilidad Municipal (EVP) y Referendum. Considerando los datos del IBGE del Censo Demográfico de 2010 y previsión de la población de 2015, así como los criterios constantes en el Proyecto de Ley Complementaria, se hizo un levantamiento poblacional de todos los 5.569 municipios y sus distritos. Con el levantamiento de esos datos fue posible hacer un mapeamiento de las posibilidades de creación de municipios, por Estado de la federación y por regiones brasileñas.

Palabras clave: Territorio. Congreso Nacional. Nuevos Municipios

\section{Introdução}

Este artigo tem por objetivo fazer uma análise sobre o último Projeto de Lei Complementar nº. 199/2015, aprovado pelo Senado Federal e em tramitação na Câmara Federal, que regulamenta a criação, desmembramento, fusão e incorporação de novos municípios no Brasil. Caso venha a ocorrer alguma modificação na Câmara, será novamente retornado para o Senado, que fará nova deliberação e, se aprovado, irá para o sancionamento presidencial.

O Projeto $\mathrm{n}^{\circ} .199$ tem origem no PLS n 104, de 2014 - Complementar (PLS n ${ }^{\circ}$ 104, de 2014,) que, por sua vez, originou-se do PLS nº. 98, de 2002 - Complementar. O PLS nº. 104, de 2014. Assim, trata-se de matéria que vem sendo debatida ao longo de duas décadas no Congresso.

Nesse sentido, este artigo representa um acúmulo de leituras referentes à criação de novos municípios no Brasil. Especificamente para a elaboração da análise proposta do Projeto de Lei do Senado $n^{\circ}$. 199, de 2015, em que foi necessário um levantamento das diversas propostas de Projetos de Lei Complementar sobre a criação, a incorporação, a fusão e o desmembramento de munícipios em tramitação no Congresso Nacional.

A análise do Projeto de Lei Complementar terá como primeiro aspecto, uma consideração inicial de que o mesmo trata de uma politica pública territorial. Decorre de vários anos da tramitação e de diversas propostas debatidas no Congresso Nacional, em que ocorreram várias contribuições não só dos deputados e senadores, como também de seguimentos da sociedade e estudiosos do tema. 
O Projeto de Lei Complementar 199/2015 é resultante de vários outros Projetos de Lei apresentados no Senado e Câmara. As diversas contribuições levaram a elaboração de uma proposta mais ampla, o que conduz a uma compreensão de uma politica territorial de estado, utilizando o conceito clássico de território utilizado na Geografia.

Uma segunda ênfase se refere a análise de alguns critérios específicos constantes do Projeto de Lei Complementar. Não se restringe à descrição do que é proposto na Lei. Como também, algumas considerações especificamente sobre três aspectos fundantes do Projeto de Lei: limites mínimos de população, Estudo de Viabilidade Municipal (EVM) e Referendum.

A necessidade de regulamentação do Artigo 18, parágrafo $4^{\circ}$ da Constituição Federal levou a um novo debate ao processo de criação de novos municípios. A Emenda Constitucional (EC) $n^{\circ} .15 / 96$ estabelece que a criação, a incorporação, a fusão e o desmembramento, far-se-ão por Lei estadual, em conformidade com Lei Complementar Federal.

A nova redação do Artigo 18, parágrafo $4^{\circ}$, os legisladores deparam com a necessidade de uma regulamentação, que possa estabelecer dispositivos legais às Assembleias Legislativas de todos os Estados para que de fato e direito as mesmas possam aprovar a criação, a incorporação, a fusão e o desmembramento de novos municípios partindo de Lei Estadual (aprovada pela Assembleia Legislativa e, posteriormente, sancionada pelo Governado de Estado).

Artigo 18, parágrafo $4^{\circ}$ estabelece que para cada Assembleia Legislativa Estadual aprove a criação a incorporação, a fusão e o desmembramento crie um novo município é necessário: (i) existência de uma Lei Complementar Federal; (ii) divulgação dos estudos de viabilidade municipal, apresentados e publicados na forma da lei; e (iii) consulta prévia, mediante plebiscito, às populações dos Municípios envolvidos.

Entretanto, no período de 1996 a 2017, não se tem uma Lei Complementar Federal aprovada. O Congresso Nacional já aprovou vários Projetos de Lei Complementar e todos sofreram vetos presidenciais.

Para ilustrar melhor os critérios constantes no Projeto de Lei Complementar, foram pesquisados dados do IBGE para levantar a população de todos os 5.569 municípios e seus distritos, referentes ao quantitativo da população do ano de 2015.

Com o levantamento desses dados foi possível fazer um mapeamento das possibilidades de criação de municípios, por estado da federação e por regiões brasileiras. 


\section{Território e Política de Estado: princípio central na análise do Projeto de Lei Complementar}

Parte-se do pressuposto de que a Lei Complementar que irá estabelecer as regras gerais para a criação, fusão, desmembramento de novos municípios, é uma política territorial de estado. Dois motivos justificam esse principio: (i) em tese, a mudança na legislação, tratase do domínio do território por parte do Estado. Embora se reconheça que a formação territorial não se restrinja às ações estatais, historicamente, manteve-se, fortemente, articulada com estas. Por essa razão, o conceito de território perpassa pela discussão das relações de poder na sociedade em diferentes escalas e contextos históricos, vez que, contraditoriamente, o território é não apenas produto das políticas públicas, mas condição para sua sustentação e manutenção, e (ii) na elaboração dessa política territorial procura-se definir, com clareados fatos, quem decide o quê, quando, com que consequências e para quem. São definições relacionadas com a natureza do regime político em que se vive, com o grau de organização da sociedade civil e com a estrutura política vigente.

$\mathrm{Na}$ Lei Complementar proposta infere-se um conceito de território com uma ênfase político-administrativa, isto é, como o território nacional, espaço físico onde se localiza uma nação; um espaço onde se delimita uma ordem jurídica e política, um espaço medido e marcado com suas linhas, limites e fronteiras. Entretanto, mesmo tendo uma vertente ideológica de imposição e demonstração de soberania, é importante a compreensão de que a Lei Complementar estabelece parâmetros gerais, e ao ser regulamentado pelos Estados da federação pode propiciar oportunidades de ampliar essa concepção de limite físico de um espaço, criando condições de analises do território também com um alcance de ideais que não se associam a limites, fronteiras físicas, mas sim pelo alcance dessas relações de poder, exercido por pessoas ou grupos.

O conceito de política estatal relaciona-se com diretrizes, princípios norteadores de ação do poder público; regras e procedimentos para as relações entre poder público e sociedade, mediações entre atores da sociedade e do Estado (ELENALDO, 2002). A Lei Complementar é uma política explicitada, sistematizada, formulada em Lei que orienta ações que envolvem aplicações de recursos públicos.

Enquanto uma política estatal traduz, no seu processo de elaboração e implantação e, sobretudo, em seus resultados, formas de exercício do poder político, envolvendo a distribuição e redistribuição de poder, com a necessidade de referendo popular e pode levar ao debate da repartição de custos e benefícios sociais. 
A política territorial presente na Lei Complementar objetiva promover estabelecimento de critérios gerais válidos para todo o país. Estabelece como pode ser criado um município, mas também trata de incorporação de vários territórios (incorporação de um distrito com outro distrito, para ser criado um novo município), fusão de um município com outro município formando um novo município e desmembramento de territórios, possibilitando a criação de um novo município.

Cumpre também a função de regular conflito entre os diversos Estados da federação, que estabelecem parâmetros diferentes de criação de novos municípios, na busca de maior possibilidade de aquisição de recursos públicos federal. Assim procura resolver essas contradições de interesses que não se resolvem por si mesmas e necessitam de mediação, ou seja, de uma Lei Federal.

É uma política institucional que traduz mediações entre interesses e valores dos diversos estados federadas, que se defrontam em espaços públicos para negociar soluções conjuntas. Essa negociação está, principalmente, na distribuição de fundos públicos (mais diretamente o Fundo de Participação dos Municípios (FPM)), que constituem referência e base para o orçamento municipal. Relaciona-se, também, na perspectiva de buscar equiparar as disparidades regionais, ao considerar as realidades locais de cada região brasileira.

Mesmo sendo uma Lei aprovada pelo Congresso, que é um dos poderes do Estado, e passível de ser vetada por outro poder (Executivo) como aconteceu em dois momentos mais recentes.

O que caracteriza as políticas estatais nessa perspectiva é a tentativa de processar as demandas do próprio sistema político. Assim, as políticas estatais compreendem um conjunto de procedimentos que são destinados a resolução em torno da alocação de bens e recursos públicos visando responder as demandas que pressionam o sistema político.

Com base nessa análise pode-se concluir que dentro do âmbito econômico e claro, de desenvolvimento, das políticas territoriais estatais existe a "materialização" das estratégias que constituem as políticas ou programas dentro do território onde há o domínio e a relação de poder (ELENALDO, 2002).

\section{Análise de alguns critérios específicos constantes do Projeto de Lei Complementar $\mathbf{n}^{\mathbf{0}}$. 199/2015 em tramitação no Congresso Nacional}

Três critérios foram analisados inseridos no Projeto de Lei Complementar $\mathrm{n}^{\circ}$. 199/2015: (i) Os limites mínimos de população, por regiões brasileiras, para criação de 
PEREIRA, L. B.

municípios ou desmembramento; (ii) Estudo de Viabilidade Municipal (EVM), levando em consideração, as viabilidades econômico-financeira, político-administrativa e socioambiental e urbana. Como também comentários sobre a elaboração, aprovação e publicidade do Estudo de Viabilidade Municipal e, (iii) a realização de Plebiscito.

\section{Os limites mínimos de população para criação de municípios ou desmembramento e a desigualdade na ocupação territorial das regiões brasileiras}

O Projeto Complementar 199/2015 estabelece um valor limite de população para a criação de novos municípios por região (6.000 mil habitantes para as regiões Norte e Centro Oeste, 12.000 mil para o Nordeste e 20.000 para as regiões Sudeste e Sul). Segundo os diversos proponentes, esses limites foram estabelecidos conforme a densidade populacional média de cada região brasileira. Nesse sentido, um limite menor para as regiões com menor densidade demográfica e um limite maior para àquelas com maior densidade demográfica.

A taxa de densidade demográfica estabelece um percentual relacionado a divisão da população total com a área (no caso de cada região). Apesar de ser uma taxa reconhecida como relevante, pois fornece uma relação de número de habitantes por quilômetro quadrado, não dá uma dimensão da forma de como a população está distribuída pela área, ou seja, com o processo de urbanização constante em nosso país, a população tende a concentrar mais nas metrópoles e centros maiores.

Essa observação é relevante, porque se exige o mesmo valor de população para um Distrito que quer se emancipar e que fica localizado no interior de um Estado distante de grandes centros urbanos, de outro que faz divisa com a sede de uma capital e que, muitas vezes, representa mais um bairro do que propriamente um distrito.

O maior exemplo dessa situação pode ser verificado no estado de São Paulo. O município de São Paulo possui o distrito sede e diversos outros distritos. O município de São Paulo, excluindo a sede, possui 96 outros Distritos registrados no IBGE (2015), sendo na realidade bairros. Somente três distritos (Barra Funda, Pari e Marcilac) possuem população abaixo do critério estabelecido pelo Projeto Complementar. Em outras palavras, 93 distritos ultrapassam o limite mínimo de população estabelecido e, pelo critério populacional, podem se constituir em novos municípios.

No município de Belém, outros sete distritos também estariam nessa situação. E assim tem-se vários exemplos nos municípios que são capitais do país. 
PEREIRA, L. B.

A Tabela 01 demonstra os dados referentes a cada Estado e somatório por Região, de acordo com o critério da população estabelecido pelo Projeto de Lei Complementar 199/2015. De acordo com o critério do mínimo populacional, referente IBGE (2015), poderiam ser criados 206 novos municípios no país.

No total na região Norte, poderia ser criados 71 novos municípios (56 só no Estado do Pará, ou seja, aproximadamente 80\%) no que concerne aos municípios que possuem Distritos, que podem se emancipar (tendo como referencial o critério da população).

Quanto à região Nordeste, os estados do Ceará, Pernambuco e Bahia são aqueles que possuem um quantitativo de distritos próximo com possibilidades de emancipar, mas que não são em quantidade numerosa.

Na região Sudeste, o estado de São Paulo é que possui a maior quantidade de distritos dentro do critério populacional. No total, 31 distritos com possibilidades de serem emancipados (sem considerar os distritos que compõem o município de São Paulo, conforme destacado anteriormente).

Nas Regiões Sul e Centro Oeste também não existem uma quantidade elevada de distritos com possibilidades de serem emancipados.

De acordo com os mesmos dados do IBGE (2015), do Projeto de Lei Complementar último vetado pela presidenta Dilma Roussef até o atual Projeto 199/2015, ocorreu uma redução significativa na quantidade de distritos aptos a serem emancipados de acordo com o critério da população. Nas regiões Nordeste, Sudeste e Sul, em que os valores mínimos aumentaram. Na região Nordeste estava apto a emancipar 91 distritos (critério da população em torno de 8.500 habitantes), no atual Projeto reduziu para 41 (critério da população em torno de 12 mil habitantes). Na região Sudeste reduziu de 101 (critério de 12 mil habitantes), para 73 (critério de 20 mil habitantes). Na região Sul, com os mesmos critérios da região Sudeste, a redução foi de 23 para 13.

Tabela 1 - Estimativas da População Residente no Brasil e Unidades da Federação com Data de Referência em $1^{\circ}$ de julho de 2015 e Quantidade de Distritos de acordo com o Projeto Complementar 199/2015.

\begin{tabular}{l|c|c|c}
\hline $\begin{array}{l}\text { Brasil, Regiões e Unidades da de Distritos aptos a serem } \\
\text { Federação }\end{array}$ & $\begin{array}{l}\text { Quantidades de } \\
\text { emancipados de acordo com critério da População } \\
\text { de acordo com o Projeto PLS n }\end{array}$ \\
\hline Brasil & $\mathbf{2 0 6}$ \\
\hline Região Norte & & $\mathbf{7 1}$ \\
\hline Rondônia & & 5 \\
\hline Acre & & 0 \\
\hline
\end{tabular}


PEREIRA, L. B.

\begin{tabular}{|c|c|}
\hline Amazonas & 7 \\
\hline Roraima & 0 \\
\hline Pará & 56 \\
\hline Amapá & 3 \\
\hline Tocantins & 0 \\
\hline Região Nordeste & 41 \\
\hline Maranhão & 2 \\
\hline Piauí & 0 \\
\hline Ceará & 12 \\
\hline Rio Grande do Norte & 0 \\
\hline Paraíba & 1 \\
\hline Pernambuco & 11 \\
\hline Alagoas & 0 \\
\hline Sergipe & 0 \\
\hline Bahia & 15 \\
\hline Região Sudeste & 73 \\
\hline Minas Gerais & 10 \\
\hline Espírito Santo & 7 \\
\hline Rio de Janeiro & 25 \\
\hline São Paulo & 31 \\
\hline Região Sul & 13 \\
\hline Paraná & 1 \\
\hline Santa Catarina & 9 \\
\hline Rio Grande do Sul & 3 \\
\hline Região Centro-Oeste & 8 \\
\hline Mato Grosso do Sul & 1 \\
\hline Mato Grosso & 4 \\
\hline Goiás & 3 \\
\hline
\end{tabular}

Fonte: IBGE. Diretoria de Pesquisas - DPE - Coordenação de População e Indicadores Sociais - COPIS. Estimativas da População Residente com data de Referência em $1^{\circ}$ de julho de 2015. Elaborado por Lucas B. Pereira, 2017.

* Na seleção dos distritos optou-se por estabelecer um critério de 5\% de variação da população para mais ou para menos.

* No estado de São Paulo não estão incluídos os distritos que compõem o município de São Paulo

* Exclui o Distrito Federal.

Milton Santos (2001), tendo como referência o entendimento da existência de uma desigualdade territorial em nosso país, interpreta o nosso território com base na existência de variáveis, ou seja, de situações características como as zonas de densidade e de rarefação, a fluidez e a viscosidade do território, os espaços da rapidez e da lentidão, os espaços luminosos 
e os espaços opacos. Inseridos nesse contexto, os espaços que mandam e aqueles que obedecem.

De acordo com os dados contidos na tabela 01, a explicação da maior concentração ou não de municípios nas diversas regiões brasileiras ou a maior possibilidade de determinados Estados da federação possuírem condições mais propícias de criarem novos municípios, está na compreensão de como se articulam essas variáveis explicitadas por Milton Santos (2001) e não só, necessariamente, na existência de uma Lei Complementar que irá "favorecer" ou "prejudicar" a criação de novos municípios.

\section{Estudo de Viabilidade Municipal (EVM): algumas considerações}

O Estudo de Viabilidade Municipal (EVM) está previsto na Emenda Constitucional nº. 15 de 1996. No entanto, sem uma definição clara de como deverá ser o seu desenvolvimento. O Projeto Complementar 199/2015 procura definir as características do EVM, que constitui condição necessária à alteração dos limites municipais e deve oferecer parecer conclusivo sobre a viabilidade econômico-financeira, político-administrativa, socioambiental e urbana.

Conforme prevê o Projeto de Lei, o EVM é fundamental para a criação de um novo município. Na realidade ele é um documento público de caráter técnico-político. Esse estudo só ocorrerá se for aprovado pela Assembleia Legislativa de cada Estado da federação o requerimento de criação, desmembramento, fusão e incorporação de novos municípios, que tem como pré-requisito fundamental o limite populacional.

\section{Viabilidade econômico-financeira}

A viabilidade econômico-financeira deverá ser demonstrada com base em algumas informações já estabelecidas, tendo a necessidade, quando for o caso, de incluir memórias de cálculo.

O Projeto Complementar 199/2015 estabelece a necessidade de uma estimativa projetada para o exercício de realização do estudo para os dois anos seguintes de: (i)receitas de arrecadação própria, levando em consideração, apenas os agentes econômicos já instalados, com base na arrecadação dos três anos anteriores ao da realização do estudo; (ii) receitas de transferências federais e estaduais, com base nas transferências recebidas nos três anos anteriores ao da realização do estudo; (iii) despesas com pessoal, custeio e investimento, dívidas vencíveis e eventuais restos a pagar que possam vir a ser transferidos do Município de origem, com base nas despesas realizadas nos três anos anteriores ao da realização do estudo; 
PEREIRA, L. B.

e (iv) resultado primário, com base nos resultados dos três anos anteriores ao da realização do estudo.

Estabelece também a indicação das seguintes estimativas de receitas: (i) das estimativas de receitas e despesas, da possibilidade de cumprimento da aplicação dos mínimos constitucionais nas áreas de educação e saúde e de atendimento na prestação dos serviços públicos de interesse local; (ii) das estimativas de receitas e despesas, da possibilidade de cumprimento dos dispositivos da Lei Complementar $n^{\circ} 101$, de 4 de maio de 2000; e, (iii) as receitas de arrecadação própria, divididas pelo número de habitantes, terão valor superior àquele observado em dez por cento dos Municípios do Estado com menor valor para este indicador.

As receitas arrecadadas, por um município ou distrito, refletem o seu grau de autonomia. Quanto maior o volume de tributos arrecadados, menor a dependência das transferências provenientes dos governos estadual e federal. Os municípios ou Distritos que possuem um quantitativo maior de população, do que aqueles limites estabelecidos pela Lei Complementar tende a ter sua receita maior.

Nesse sentido, a forma de distribuição dos recursos governamentais, principalmente o Fundo de Participação dos Municípios (FPM) tende a financeiramente beneficiar os municípios menores. Municípios pequenos têm dificuldades de ampliação da sua capacidade tributária e, assim, as finanças municipais são reforçadas através do crescimento na participação das transferências constitucionais (GOMES; MAC DOWELL, 2000).

É em função dessa relação que surgem os questionamentos pela não emancipação de diversos Distritos, que possuem pequena população, mesmo dentro dos critérios estabelecidos no Projeto de Lei Complementar, estes, por sua vez, terão sempre a necessidade de suporte financeiro adicional do Governo Federal e dos Estados.

\section{Viabilidade político-administrativa}

A viabilidade politico-administrativa procura essencialmente observar a proporção entre o número de servidores e a população estimada na área territorial dos Municípios envolvidos, por meio das seguintes informações: (i) número de representantes que integrarão a Câmara de Vereadores; e (ii) estimativa do número de servidores públicos necessário para compor o Poder Executivo e o Poder Legislativo municipais.

\section{Viabilidade socioambiental e urbana}


PEREIRA, L. B.

O estudo de viabilidade socioambiental e urbana, além das informações estabelecidas no Projeto Complementar, deverá levantar alguns problemas de ordem ambiental (potenciais impactos ambientais) e urbana, denominados no Projeto Complementar de passivos, que deverá definindo preliminarmente qual município (se o existe dentro de novos parâmetros e o novo a ser criado) deverá assumir as responsabilidades.

Dentre os passivos, um que até hoje gera muitos transtornos, e porque não dizer disputas judiciais, se refere aos limites municipais. Nesse caso, referindo-se as divisas entre o município que será criado e os demais. Essas disputas judiciais ocorrem quando os limites não estão bem estabelecidos, no momento da aprovação da Lei que cria o município. Hoje esse aspecto é importante, principalmente para os municípios menores, porque a perda de alguma parte do território pode representar perda de população e, consequentemente, redução na faixa do FPM.

Conforme prevê o Projeto de Lei Complementar os limites deverão ser estabelecidos com base nas seguintes condições: (i) os limites dos Municípios devem ser descritos preferencialmente por acidentes físicos, naturais ou artificiais, perfeitamente identificáveis no terreno e representados no mapeamento de referência, o qual deverá estar vinculado ao Sistema Cartográfico Nacional (SCN); e, (ii) quando os limites dos Municípios forem descritos por linhas imaginárias, devem ser informadas as coordenadas geográficas de seus pontos extremos e de seus pontos intermediários, todas vinculadas ao Sistema Geodésico Brasileiro (SGB), recaindo tais pontos, de preferência, sobre acidentes físicos, naturais ou artificiais, perfeitamente identificáveis no terreno.

A análise da estrutura urbana é outro ponto fundamental do estudo. Na essência, o objetivo posto para o estudo desse tema é identificar se existe um aglomerado urbano contínuo, como vem sendo o crescimento atual e perspectiva futura quanto ao aspecto populacional, de número de imóveis residenciais e comerciais. Ou seja, um centro urbano que esteja consolidado dentro dos padrões de uma pequena cidade e esteja em rede com os municípios próximos.

Nesse centro urbano deverão ser analisados os patrimônios públicos existentes, bem como a existência de serviços básicos para a população: redes de abastecimento de água, esgotamento sanitário e energia, produção de resíduos sólidos e efluentes, recursos hídricos e formas de manejo de águas pluviais.

Outros aspectos vinculados à ocupação do solo urbano, são a identificação de áreas protegidas ou de destinação específica, tais como unidades de conservação e áreas indígenas, quilombolas ou militares e malha viária. 
Esses critérios postos como referência para o EVM sobre a questão urbana precisam ser ampliados. Daí o fato de que a sua elaboração precisa de fato ser acompanhada e envolver uma equipe interdisciplinar.

Pensar a cidade hoje é pensar, também, sob a perspectiva de que ela é o espaço onde os direitos do cidadão podem ou não se materializar. É claro que as pessoas ao reivindicarem um novo município, imaginam e procuram buscar que esses direitos efetivamente ocorram e sejam assegurados. Buscam apoio nas políticas governamentais para a realização de ações que proporcionem mais desenvolvimento urbano visando melhor bem estar social. Nesse sentido, para a criação de mais um município, deve-se inserir a compreensão de que é necessária incluir esse "novo urbano local" dentro de uma política urbana mais ampla do Estado vinculada a viabilização dos direitos fundamentais do ser humano.

Os problemas enfrentados pela população dos Distritos, são os referentes à falta de acesso à educação, à saúde e a outros bens sociais, e isso requer novas estruturas sociais e econômicas que possibilitem reduzir a ruptura social causada pela exclusão, pobreza, desemprego e criminalidade.

Elaboração e aprovação do Estudo de Viabilidade Municipal

Ao considerar as indicações estabelecidas no Projeto Complementar, o EVM deverá ser conclusivo quanto à viabilidade ou não da criação, fusão, incorporação e desmembramento dos municípios a serem criados. Conforme estabelece a Lei Complementar, esse estudo deverá ser contratado e custeado pelos governos estaduais com instituições públicas ou privadas de comprovada capacidade técnica. Existe a necessidades de Audiências públicas para o envolvimento da população interessada.

A perspectiva de criar possibilidades de envolvimento daqueles interessados diretamente, e da sociedade como um todo, pode ser considerado como um ponto positivo. As discussões, principalmente com a comunidade local, podem levantar aspectos importantes para serem inseridos no estudo. No entanto, a relevância complementar vem em fomentar a participação comunitária. A mesma não deve ser induzida apenas a atender a obrigação legal. Nesse sentido, tem-se uma participação enganosa ou aparente. A participação é relevante, num processo de contínuas informações e debates, na qual a presença da comunidade (cidadão) se faz em diversos momentos.

A participação não deve se limitar a referendar o processo. É o momento de discutir os problemas e propor soluções. Ser cidadão participativo, não significar somente fazer as cobranças, como também ser corresponsável, nas soluções dos mesmos. 
PEREIRA, L. B.

Ao ser apreciado pelas Assembleias Legislativas estaduais, o estudo, conforme prevê o Projeto Complementar, só será aprovado se não acarretarem: (i) a perda da continuidade territorial e da unidade histórico-cultural do ambiente urbano; (ii) a quebra da continuidade territorial de qualquer um dos Municípios envolvidos, exceto no caso de ilhas e arquipélagos; (iii) o advento de Municípios cujos limites territoriais sejam exclusivamente a área de um único Município; ou (iv) a alteração das divisas territoriais dos Estados.

Importante salientar que serão vedados a criação e o desmembramento de Municípios quando implicarem inviabilidade de qualquer dos municípios envolvidos.

\section{Da publicidade do Estudo de Viabilidade Municipal}

Conforme estabelece a Lei Complementar os EVM's ficarão à disposição de todo cidadão durante um prazo mínimo de cento e vinte dias, em local acessível nos núcleos urbanos dos Municípios envolvidos, na Assembleia Legislativa do respectivo Estado da federação e também poderá ser acessado por qualquer cidadão na internet.

As Assembleias Legislativas cumprirão um procedimento de maior relevância nesse processo. Será de responsabilidade das mesmas: (i) colocar o EVM em consulta pública através de audiências públicas; em cada um dos núcleos urbanos dos Municípios envolvidos, para esclarecimento da população. (ii) publicar na íntegra, no órgão oficial de imprensa do Estado e em resumo, em jornal de grande circulação regional, contendo os principais dados e conclusões conforme estabelece o Projeto de Lei Complementar.

Em caso de recomendações a Assembleia Legislativa compilará as críticas e sugestões feitas ao EVM e decidirá pela aprovação integral, rejeição integral ou reelaboração total ou parcial do EVM.

No caso da decisão pela reelaboração parcial ou integral do EVM, a instituição responsável pela elaboração do Estudo será convocada a realizar a tarefa e, posteriormente, decidirá novamente pela aprovação integral ou rejeição integral. Não havendo aprovação integral a Assembleia Estadual comunicará o fato ao Governador do Estado, que providenciará a contratação de outra instituição para refazer ou adequar o EVM.

Em sendo aprovado o novo município, deverá ocorrer na sequência, à escolha de um poder executivo (prefeito e vice) e um poder legislativo (vereadores). É importante despertar no cidadão, para pensar em construir uma futura gestão democrática, com características de liberdade e não de perseguição ao cidadão, transparente, eficiente e eficaz, com controle social, pode ser possível e não entendê-la como utópica. 


\section{A realização de plebiscito}

A Lei federal 9.709/1998 regulamenta a execução do disposto nos incisos I, II e III do art. 14 da Constituição Federal, ao estabelecer que a soberania popular seja exercida pelo sufrágio universal e pelo voto direto e secreto. Uma das normas constitucionais é o Plebiscito. Essa é uma consulta formulada ao cidadão para que delibere sobre matéria de elevada relevância.

Em se tratando do tema posto, o plebiscito destinado à criação, à fusão, à incorporação e ao desmembramento, de municípios, envolverá no processo decisório os moradores eleitores tanto do município a ser criado, como do "município mãe". O mesmo será convocado pela Assembleia Legislativa e coordenado pelo Tribunal Regional Eleitoral (TRE) de cada unidade da federação. O plebiscito é o último requisito para a emancipação.

Dentre os critérios estabelecidos na Lei Complementar o plebiscito e o estudo de viabilidade municipal reforçam o princípio de que não basta somente o critério populacional e econômico para que um município seja criado. Eles podem representar os principais obstáculos ou motivações para a criação de novos municípios.

A depender da situação de cada Distrito a ser emancipado (mesmo tendo a população exigida) podem ter maiores ou menores as possibilidades de aprovação em um plebiscito devido aos interesses postos e ao próprio critério da população e número de eleitores. Se uma população de um distrito a ser emancipado for maior do que a da sede do município, a situação será mais favorável. Ao contrário, a situação torna-se mais difícil se tiverem a mesma proporção de população e eleitores as chances são difíceis. Claro que esse raciocínio parte do princípio de que existe uma divergência quanto à aceitação entre as partes. A necessidade de diálogo na busca do consenso deverá ser um mecanismo político de grande importância entre a população envolvida.

Em muitas situações a emancipação de distritos será praticamente consensualizada. $\mathrm{Na}$ maioria das vezes, existe uma situação política que vem do processo de eleição municipal, em que a escolha do gestor da sede ou de outro Distrito maior é pautada pela discórdia permanente. Nesse caso, o plebiscito será uma mera formalidade, pois existe o interesse de ambas as partes.

Os interesses diferenciados podem se expressar por diversos motivos. Distritos pertencentes a grandes cidades tendem a ter mais dificuldades, seja por motivo da desproporção do eleitorado, seja por motivo de perda de arrecadação. Citando exemplo do Estado da Bahia, tem-se o distrito de Humildes que concentra grande parte das indústrias do município de Feira de Santana e o distrito de Arraial d'Ajuda, pertencente ao município de Porto seguro, também na Bahia, concentra uma economia na área do turismo, com 
representativa quantidade de hotéis e pousadas gerando intenso movimento de atividades turísticas que representa uma arrecadação expressiva para os cofres do município de Porto Seguro.

Muitos desses exemplos poderiam ser citados nos demais Estados da federação. A exigência de aprovação em plebiscito leva a maior reflexão sobre a emancipação por parte da população local. Mesmo não participando diretamente no processo da elaboração e divulgação do Estudo de Viabilidade Municipal-(EVM), na votação do plebiscito a população toma conhecimento e se manifesta através do voto.

\section{Considerações finais}

Independentemente da existência ou não de uma forma institucionalizada de regulamentação territorial, o território será apropriado e territorializado.

Acredita-se que a Lei Complementar pode ser interpretada como uma política estatal territorial. Se a mesma tem sentidos políticos distintos, se é uma política representativa ou não, no sentido de atender a maior parcela da população, são aspectos que devem levar ao debate. E que esse debate é inerente a forma de como a sociedade territorializa seus espaços, em detrimento à grande extensão territorial que o Brasil possui. .

Nesse sentido é que se considera importante o entendimento de que se trata de uma politica estatal territorial e que nessa política o município tem uma representatividade. Para Castro (2005, p.134) o município é uma escala e um território político por excelência, sendo que "[...] é no conhecimento da dinâmica da ocupação do território, da organização das sociedades locais e dos seus interesses que as decisões políticas e os modos de organização do território do país, como resultados concretos dessas decisões, adquirem significado".

Um olhar atento para o território brasileiro mostra que é preciso ponderar que há toda uma rede entre municípios de pequenas localidades, parte delas reconhecida como distritos. É comum no Brasil se encontrar entre estas localidades algumas mais adequadas do que muitas sedes de municípios no cumprimento de funções urbanos, número de habitantes e equipamentos e meios de consumo coletivo.

O Projeto Complementar $n^{\circ}$. 199/2015 é uma resposta ao veto. Na mensagem encaminhada pelo poder executivo ao Congresso Nacional é destacada na justificativa a argumentação relacionada ao problema da responsabilidade fiscal, ou seja, a aprovação de um Projeto com esse objetivo aumenta as despesas com as novas estruturas municipais sem que haja a correspondente geração de novas receitas (BRASIL, 2014). 
PEREIRA, L. B.

A justificativa contida na mensagem do veto representa um momento conjuntural econômico e político brasileiro, dada às condições financeiras do setor público e a composição dos representantes no Congresso Nacional.

A sociedade brasileira, através de suas representações dos diversos seguimentos organizados, deve se inteirar mais sobre as decisões sobre essa questão, que deve remeter mais ao debate sobre o desenvolvimento territorial.

Com essas ponderações, não se está afirmando, como dito anteriormente, de que a aprovação de uma Lei será o fator preponderante para criar mais municípios no País.

\section{Referências}

BRASIL. Casa Civil. Mensagem n ${ }^{\circ} 250$ de 2014. Diário Oficial [da] União. Brasília, 24 ago., 2014.

. Emenda Constitucional $n^{\circ} 15$ de 12 de setembro1996. Lex: legislação federal, Brasília Disponível em: <www.planalto.gov.br.ccivil-03/constituicao/emendas/EMC/emc15$\underline{\mathrm{htm}}>$. Acesso em 23/11/2015

. Congresso. Senado. Projeto de Lei Complementar - PSL, n ${ }^{\circ}$ 199/2015 de autoria do senador Flexa Ribeiro. Dispõe sobre o procedimento para a criação, a incorporação, a fusão e o desmembramento de Municípios, para regulamentar o $\S 4^{\circ}$ do art. 18 da Constituição Federal. Diário Oficial [do] Senado Federal Brasília, DF, 2015.

CASTRO, Iná Elias de. Geografia Política: território, escalas de ação e instituições. Rio de Janeiro: Bertrand Brasil, 2005. 304p.

ELENALDO, Celso Teixeira. Políticas Públicas: o papel das politicas públicas. Bahia: AATR, 2002. 123p.

GOMES, G. M.; MAC DOWELL, M. C. Descentralização política, federalismo fiscal e criação de municípios: o que é mau para o econômico nem sempre é bom para o social. Texto para discussão n. ${ }^{\circ}$ 706, Brasília: IPEA, 2000.

IBGE. Estimativas da População Residente com data de Referência em $1^{\circ}$ de julho de 2015. Diretoria de Pesquisas (DPE). Coordenação de População e Indicadores Sociais (COPIS). Brasília, 2015.

SANTOS, Milton \& SILVEIRA María Laura. O Brasil: território e sociedade no início do século XXI. Rio de Janeiro: Record, 2001. 471p. 
Políticas públicas territoriais: a criação de novos municípios no Brasil

PEREIRA, L. B.

Recebido em: 21/03/2018

Aceito para publicação em: 30/04/2018 